Exploring placement stability for children in out-of-home care in England: a sequence analysis of longitudinal administrative data

Louise Mc Grath-Lone ${ }^{a, b *}$, Katie Harron ${ }^{a, b}$, Lorraine Dearden ${ }^{a, c}$ \& Ruth Gilbert ${ }^{a, b}$

a. Administrative Data Research Centre for England, University College London, 222 Euston Road, London, NW1 0QX, UK.

b. UCL Great Ormond Street Institute of Child Health, University College London, 30 Guilford Street, London, WC1N 1EH, UK.

c. UCL Institute of Education, University College London, 20 Bedford Way, London, WC1H 0AL, UK.

*Correspondence to: Dr Louise Mc Grath-Lone, Rees Centre, Department of Education, University of Oxford, 15 Norham Gardens, Oxford, OX2 6PY, UK. E-mail: louise.mcgrathlone@education.ox.ac.uk Phone: +44 1865611032

\title{
Acknowledgements
}

This research was funded by the Economic and Social Research Council (grant reference number ES/L007517/1) establishing the Administrative Data Research Centre for England (ADRC-E). At the time this research was conducted, KH was funded by a Sir Henry Wellcome Postdoctoral Fellowship (grant reference number 103975/Z/14/Z). Data for this study was obtained from the Department for Education; however, the findings, interpretations and conclusions expressed in this paper are entirely those of the authors. The authors would like 
to thank Profs Jonathan Scourfield and Amanda Sacker for their helpful comments on an early draft of this manuscript.

Declaration of interest: none 


\begin{abstract}
Background

To monitor stability of care, the proportion of children in England who have experienced three or more placements in the preceding 12-month period is published in government statistics. However, these annual snapshots cannot capture the complexity and heterogeneity of children's longitudinal care histories.
\end{abstract}

\title{
Objective
}

To describe the stability of care histories from birth to age 18 for children in England using a national administrative social care dataset, the Children Looked After return (CLA).

\section{Participants and Setting}

We analyzed CLA data for a large, representative sample of children born between 1992 and $1994(N=16,000)$.

\section{Methods}

Using sequence analysis methods, we identified distinct patterns of stability, based on the number, duration, and timing of care placements throughout childhood.

\section{Results}

Although care histories were varied, six distinct patterns of stability were evident including; adolescent $1^{\text {st }}$ entries (17.6\%), long-term complex care (13.1\%) and early intervention (6.9\%). Overall, most children (58.4\%) had a care history that we classified as shorter term 
care with an average of 276 days and 2.48 placements in care throughout childhood. Few children (4.0\%) had a care history that could be described as long-term stable care.

\section{Conclusions}

Longitudinal analyses of administrative data can refine our understanding of how out-ofhome care is used as a social care intervention. Sequence analysis is a particularly useful tool for exploring heterogeneous and complex care histories. Considering out-of-home care histories from a life course perspective over the entire childhood period could enable service providers to better understand and address the needs of looked after children.

Keywords: administrative data; longitudinal care histories; sequence analysis. 


\section{Exploring placement stability for children in out-of-home care in England: a sequence analysis of longitudinal administrative data}

Permanence can be defined as an emotional, physical, and legal sense of security, stability, and continuity (Thomas, 2013). Achieving a sense of permanence during childhood is important as it can help to develop and maintain a sense of attachment, belonging, and personal and cultural identity that persists into adulthood and is associated with positive life outcomes (Ranson \& Urichuk, 2008; Thomas, 2013; Boddy, 2013). For children who are in contact with social services, placement in out-of-home care represents an obvious disruption to permanence as the nature of this intervention results in a change in their home, caregiver(s) and, possibly, legal status and local community. Achieving permanence is a central goal of the children's social care system in England (Department for Education, 2015). Often, there is a focus on achieving permanence outside of the out-of-home care system through a return to living with their parents or by establishing legal permanence with an alternative family through adoption, or, more recently, through special guardianship and child arrangement orders, which set out who cares for a child and/or where they live (Department for Education, 2016). However, long-term, stable placement in foster care or a residential setting is also recognized as a route to achieving permanence within the out-ofhome care system (Boddy, 2013).

Placement changes are one aspect of care experiences that can undermine permanence for children in out-of-home care as they result in a change in where children live, who they live with and who cares for them (Department for Education, 2013). There is a large body of literature that describes associations between the stability of out-of-home care placements and a range of health, educational and social outcomes (Jones et al., 2011). For 
example, "unstable" out-of-home care placements (characterized by many and/or frequent changes) have been associated with an increased likelihood of having mental health issues (Akister, Owens, \& Goodyer, 2010; Richardson \& Lelliott, 2003), self-harm (Beck, 2006) and poor educational attainment (O'Sullivan \& Westerman, 2007). As much of the evidence in this area is from cross-sectional analyses, it is not possible to infer causality in this relationship; however, placement stability is widely considered to be an important aspect of good quality out-of-home care. For example, in the past, the UK government has used the number of placement changes a child experiences in 1 year as an indicator of the quality of out-of-home care provision (Panchamia \& Thomas, 2017). Although placement stability is no longer used as a performance indicator, it is still routinely monitored using administrative social care data. Since 2002, the Department for Education (DfE) has reported the proportion of children who have three or more placements in 1 year in their annual statistics related to looked after children. The most recent statistics show that, of the 78,150 children looked after in England on the $31^{\text {st }}$ March $2019,10 \%$ had three or more placements in the preceding year (Department for Education, 2019). However, the cross-sectional nature and short time frame of these statistics have been criticized by children in care and care leavers because they cannot fully capture the stability of their experiences (Longfield, 2017).

Longitudinal analyses of placement stability for children in care in England are limited. A recent report by the Office of the Children's Commissioner estimated that over a 4-year period, 1 in 10 children experienced five or more placement changes (Children's Commissioner for England, 2019). Several recent studies in England have focused on describing the stability of children's care placements over multiple years (Stanley, Riordan, \& Alaszewski, 2005; Mc Grath-Lone, Dearden, Nasim, Harron, \& Gilbert, 2016; Mc Grath- 
Lone, Harron, Dearden, Nasim, \& Gilbert, 2017; Neil, Gitsels, \& Thoburn, 2019) and categorizing longitudinal care histories (Sebba et al., 2015; Berridge et al., 2020). However, the limitation of such studies is that none have explored stability of care placements throughout childhood and most analyses are based on purposive and/or sub-national populations. For example, Stanley, Riordan, and Alaszewski (2005) described cumulative care histories for children in two local authorities aged 5-18 years with high levels of mental health needs. Among these 80 children, the total time in care ranged up to 16 years and almost half (48\%) had experienced three or more placements since entering care. A further limitation of the existing longitudinal evidence base is that simple descriptions of placement stability do not account for the timing of changes; yet, in life course theory, the timing and context of events are thought to affect life trajectories (Elder, 2016). For example, experiencing three or more placements during infancy may have a different effect to experiencing three or more placements as an adolescent.

Sequence analysis is an analytic technique that is often used to describe life course trajectories that account for the number, timing, and duration of life events (Abbot \& Tsay, 2000). This non-parametric, algorithm-based method also allows groups of homogenous trajectories to be identified by comparing the similarity of sequences of events, such as outof-home care placements. A small number of studies have used sequence analysis to identify differing patterns of placement stability using childhood care histories and have identified groups at risk of experiencing instability among children in the US (Havlicek, 2010) and Denmark (Andersen, 2014; Fallesen, 2014). However, sequence analysis has not been used to characterize patterns of placement stability among children in care in England. 
Achieving permanence through stable care experiences is important to children in care, care leavers, and policy makers (Department for Education, 2015; Dickson, Sutcliffe, \& Gough, 2010; Longfield, 2017; Selwyn, Wood, \& Newman, 2017); yet, our understanding of the stability of care histories in England is currently incomplete as there are no longitudinal descriptions that account for the number, timing, and duration of placements throughout childhood. The aims of this analysis were to describe the stability of care histories accounting for all placement changes, from birth to age 18 , and to determine whether there were distinct patterns of placement stability using sequence analysis.

\section{Method}

\section{Data Source}

Administrative data related to children placed in out-of-home care in England have been routinely collected by the DfE since 1992 through the Children Looked After Return (CLA). Briefly, CLA is a national, longitudinal dataset that contains child-level information related to episodes of out-of-home care, including start and end dates of each placement. These episodes can be linked over time via a unique child identifier to collate longitudinal care histories. Further details of the CLA dataset are available in Mc Grath-Lone, Harron, Dearden, Nasim, \& Gilbert (2016).

The CLA data extract for this analysis included a randomly selected sample of children who were born between $1^{\text {st }}$ January 1992 and $31^{\text {st }}$ December 1994 and had ever been placed in out-of-home care in England by age 18 for non-respite reasons $(N=16,000)$. 
Children who had only ever been placed in respite care were excluded from this analysis as some local authorities choose to record the period of time during which an agreed series of respite placements were provided, rather than the exact start and end dates of each placement (Department for Education, 2020). This sample was representative of the overall population of children in the birth cohort, in terms of demographic and care history characteristics (see Supplementary Table 1).

\section{Creating Sequences of Care Stability}

As the aim of this analysis was to describe the stability of out-of-home care placements, we used longitudinal CLA data to derive a sequence that captured the timing, number, and duration of placements that each individual child experienced from birth to age 18. We selected months as the unit of time which meant that for each child we created a sequence that contained 216 states - one for each month of their 18 years of childhood. For each month, we defined a child's state as either "not in out-of-home care", or, if they were in care, the number of the placement they were in (i.e., $1^{\text {st }}, 2^{\text {nd }}, 3^{\text {rd }}$, and so on). If a child had more than one placement in a month, we recorded their state as the number of their last out-of-home care placement in that month. This categorization meant that the sequences we created were a simplified version of children's care histories. A limitation of this choice of categorization is that being recorded as "not in out-of-home care" could include a range of heterogenous situations, such as being reunified with parents, living with a special guardian, being adopted, or living independently. Similarly, being recorded as in a care placement could include a range of settings, such as foster care, residential care, or a youth justice setting. However, as the aim of this analysis was to explore stability in terms of the changes in placement that a child experiences, we felt that this simplification was 
appropriate. Furthermore, this method of categorization had been previously applied to a similar dataset for children in care in Denmark which enabled us to make international comparisons with our results (Fallesen, 2014). Illustrative examples of sequences for 1 year of childhood are shown in Figure 1.

Among this sample of children, the total number of care placements during childhood ranged from 1 to 184 ; however, the distribution was skewed with only $2 \%$ of children having more than fourteen placements (i.e., $98^{\text {th }}$ percentile $=14$ ). Given this skewed distribution, we chose to recode children's $15^{\text {th }}$ and subsequent placements as their $14^{\text {th }}$ in order to simplify the placement sequences and reduce the computing power required to compare them. As a result of this change in coding, the complexity of care placement sequences was artificially reduced for a small proportion of children in our sample $(2.3 \%, n=368)$.

\section{Sequence Analysis of Placement Stability}

Having derived a simplified placement sequence for each individual, we then used dynamic hamming matching (DHM) to compare their similarity. We chose DHM because it does not require the user to specify the relative importance (or weight) of differences between states in a pair of sequences at a given point in time (Abbot \& Tsay, 2000; Halpin, 2012). Instead, the relative importance of differences in states is determined by the empirical data (i.e., the frequency of a difference in state at a given point in time determines how important it is). A difference in state that is frequently observed between sequences in an empirical dataset will be considered less important than one that is infrequently observed. DHM is considered to be well-suited to exploratory analyses and a less arbitrary method of 
comparing sequences than those that require a researcher to specify the relative importance of differences in sequences, such as optimal matching methods (Lesnard, 2010).

The output of DHM is a matrix of dissimilarity (or distance) scores that represent the comparability of any two sequences in a dataset (Lesnard, 2010). To identify subgroups of similar sequences in the dataset based on these dissimilarity scores, we applied Ward's clustering algorithm. This agglomerative algorithm starts with a single cluster for each observation in a dataset (i.e., 16,000 clusters of $n=1$, in this analysis). The algorithm then searches the dissimilarity matrix to identify the most similar pairs of clusters and merges (or agglomerates) them together. The dissimilarity matrix is updated and the procedure is repeated in a step-wise manner until a pre-specified number of clusters remains.

In this analysis we considered solutions with between two and twenty clusters. To identify the solution that best represented the typical patterns of stability among our sample, we considered (1) the size, homogeneity, and interpretability of the identified clusters and (2) how distinct they were, as indicated by a higher Caliński-Harabasz pseudo f-score (Milligan \& Cooper, 1985). For the solution that we selected as the most appropriate representation of the empirical data, we used a chronogram to visually summarize the stability of care histories and guide our choice of name for each cluster (or subgroup). Further details of how we selected the most appropriate number of subgroups are given in the Results section (Overview of the Chosen Clustering Solution).

\section{Variation in Patterns of Placement Stability}

For each subgroup of placement stability, we summarized and compared the key care history characteristics, including age at first entry and final exit, total time spent in care and 
the total number of placement changes. We then visualized the patterns of care placements in each subgroup using sequence index plots. We used this information to name each subgroup.

The CLA dataset does not collect information related to family characteristics or risk factors at entry to care; therefore, it was not possible to explore factors that may predict the stability of care histories as has been described for children in Denmark (Andersen, 2014; Fallesen, 2014). Similarly, the CLA dataset does not collect information about health, education or other outcomes; therefore, it was not possible to explore how differences in patterns of care placement stability may be related to outcomes. Such analyses may be possible in the future for cohorts of children who were born after 2005 as this is when the CLA dataset began collecting identifiers that allow it to be linked to other educational datasets.

Ethical approval was not required for this study as it was a secondary analysis of deidentified administrative data; however, all applications for CLA data are reviewed by an advisory panel at DfE before access to the data is granted.

\section{Results}

\section{Sample Characteristics}

Table 1 describes the demographic characteristics of the 16,000 children included in this analysis and key summary characteristics of their cumulative care histories, accounting for all placements in care throughout childhood. The total time spent in care ranged from a single day to 18 years with a mean of 32 months and a median of 15 months. In terms of the 
stability of children's care histories, the total number of out-of-home care placements from birth to age 18 ranged from 1 to 184 with a mean of 3.6 placements and a median of 2 placements.

\section{Overview of the Chosen Clustering Solution}

Among this sample of 16,000 children, there were 11,111 unique sequences of out-of-home care placements throughout childhood. However, by applying Ward's algorithm to the measures of sequence dissimilarity calculated by DHM, it was possible to cluster these diverse sequences into subgroups based on their similarity in terms of the number, duration, and timing of placements. We decided that the six-cluster solution best represented the empirical data as it had a comparatively high Caliński-Harabasz pseudo f-score (Supplementary Figure 1), indicating that the clusters were distinct from each other. Furthermore, chronograms showed that sequences within each cluster were relatively homogenous (though not completely homogenous) and that each cluster had an interpretable pattern of stability (Figure 2). We considered the seven-cluster solution but discounted it as it had a lower Caliński-Harabasz pseudo f-score than the six-cluster solution and resulted in two subgroups that accounted for $<1 \%$ of the overall sample. We also considered the four- and five-cluster solutions, which had higher Caliński-Harabasz pseudo f-scores than the six-cluster solution, but discounted them based on the interpretability of the proposed clusters (see Supplementary Figure 1 for further details).

When labelling the subgroups, we chose names based on the summary descriptive statistics of the overall subgroup (such as the median number of placements during childhood, median age at first entry to care, etc.) and the typical patterns of placements evident from a sequence index plot. This meant that there are a small minority of individuals for whom the subgroup label does not fit well; for example, $<50$ individuals in the adolescent $1^{\text {st }}$ entry group entered care before the age of 11. 


\section{Characteristics of Subgroups of Care Placement Stability}

The overall frequency and characteristics of the six subgroups of care placement stability are summarized in Table 2. Figure 2 presents a chronogram of the six subgroups. Key characteristics of each subgroup are then described in detail with an accompanying sequence index plot to illustrate individuals' placement histories. The subgroups are presented in order of relative size.

Shorter term care. The majority of children (58.4\%) had a pattern of care placement stability that could be described as shorter term care (Figure 3). These children entered care for the first time throughout childhood, from infancy to age 17 years (Table 2). On average, children spent 276 days in care in total (median $=116$ days). Overall, a third (33.0\%) were placed in care for less than 1 month in total throughout childhood and just a quarter of spent more than 1 year in care (26.1\%). Almost a third of children in this subgroup (29.8\%) reentered care at some point during childhood, but the average total number of placements was just 2.48 (median $=2$ ). When leaving care for the final time, the majority of children in this subgroup returned home (65.9\%).

Adolescent $1^{\text {st }}$ entry. Almost one in five children $(17.6 \%)$ had a pattern of care placements that could be best categorized as an adolescent $1^{\text {st }}$ entry (Figure 4). The median age at first entry to care was 15 years in this subgroup (Table 2). A quarter of children in this cluster (23.6\%) re-entered care at some point during childhood and the average number of total placements was 3.13 (median $=2$ ). On average, children spent 2.5 years in care in total ( median $=2.3$ years) and $76.6 \%$ remained in care until the age of 18 years. When leaving care for the final time, most children moved to independent living (41.3\%) or aged out of the care system (39.6\%). It should be noted that this subgroup does not include all children who 
entered care for the first time as adolescents as they may have been assigned to a different subgroup based on their pattern of placements.

Long-term complex care. In total, $13.1 \%$ of children had a sequence of care placements that could be described as long-term complex care (Figure 5). Children in this cluster entered care aged $<16$ years and the median age at first entry to care was 7 years (Table 2). On average, children spent 8.7 years in care in total (median $=8.4$ years). Compared to other subgroups, these children had the greatest number of placements overall, ranging from 1 to 184 . On average, children had 8.97 placements throughout childhood (median $=7$ ) and more than a quarter (28.1\%) had $10+$ placements in total. The majority of children in this subgroup re-entered care at some point during childhood $(58.3 \%)$ and $80.8 \%$ remained in care until the age of 18 years. When leaving care for the final time, most children aged out of the care system (43.0\%) or moved to independent living (36.9\%).

Early intervention. Overall, $6.9 \%$ of children had a pattern of care placements that could be described as early intervention (Figure 6). All children in this subgroup first entered care before age 9 years and the median age at first entry was 3 years (Table 2). On average, children spent 4.4 years in care in total (median $=4.1$ years) and $78.9 \%$ left care before adolescence (i.e., before age 11 years). Less than half of children in this subgroup (43.7\%) reentered care at some point during childhood and the average total number of placements was 4.95 (median $=4)$. When leaving care for the final time, $61.9 \%(n=685)$ of children were adopted or placed with a guardian. A further $22.4 \%(n=247)$ returned home.

Stable $2^{\text {nd }}$ placement. In total, $2.4 \%$ of children had a sequence of care placements that could be classified as a stable $2^{\text {nd }}$ placement (Figure 7). This subgroup was characterized by a comparatively short $1^{\text {st }}$ placement followed by a longer $2^{\text {nd }}$ placement (median of 201 
days and 7.9 years, respectively). All children in this subgroup entered care for the first time before age 12 years (Table 2). Children in this subgroup spent the longest time in out-of-home care, with an average of 10.3 years in total (median $=10$ years). Overall, a quarter of children (25.1\%) re-entered care at some point during childhood and the average number of total placements was 3.89 (median $=3$ ). The majority of children $(88.2 \%)$ remained in care until the age of 18 years and when leaving care for the final time, a third moved to independent living (33.8\%) and almost half aged out of the care system (49.5\%).

Stable $1^{\text {st }}$ placement. Overall, $1.6 \%$ of children had a sequence of care placements that could be described as a stable $1^{\text {st }}$ placement (Figure 8). All children in this cluster entered care for the first time before the age of 13 years (Table 2). On average, children spent 8.8 years in care in total (median $=8.5$ years). Less than one in ten children in this subgroup $(9.8 \%)$ ever re-entered care and the average total number of placements was 1.98 (median $=1$ ), the lowest of the six subgroups we identified. Indeed, more than half of children (59.1\%) had just one placement in total. For children in this group, their $1^{\text {st }}$ placement was longer than subsequent placements, accounting for $88 \%$ of their total time in care on average. The majority of children in this subgroup (86.2\%) remained in care until the age of 18 years. When leaving care for the final time, approximately two-thirds of children moved to independent living or aged out of the care system ( $32.7 \%$ and $36.6 \%$, respectively) and a further one in six (15.8\%) transferred to adult social services. 


\section{Discussion}

In England, current approaches to monitoring the stability of children's care histories focus on cross-sectional descriptions of placement changes within a 12-month period. However, this approach cannot capture the complexity of children's longitudinal care histories. Our analysis was the first to explore the stability of care histories throughout childhood for children in England using longitudinal administrative data. Based on our large, representative sample of children who were born between 1992 and 1994, it was evident that children's care histories were complex with placement changes and/or exits and re-entries to care encountered on their journey through the out-of-home care system. Despite the heterogeneity of individuals' care histories, we were able to identify six patterns of out-ofhome care histories that varied in terms of the timing, duration and number of placements. Based on these placement sequences, it appears that most children in this cohort who entered out-of-home care achieved some form of stability. However, this was most often through shorter term care that ended with family reunification, adoption, or a special guardian being appointed (58.4\%), rather than within the social care system through stable, long-term $1^{\text {st }}$ or $2^{\text {nd }}$ placements $(4.0 \%)$.

The main strength of our study is that it included and accounted for the timing, number, and duration of all placements in care throughout childhood for all children, unlike other studies which have been limited to a time frame of a few years or particular subgroups of children (Longfield, 2017; Schofield, Thoburn, Howell, \& Dickens, 2007; Sinclair, Baker, Lee, \& Gibbs, 2007; Stanley, Riordan, \& Alaszewski, 2005). As a result, it is a more comprehensive and child-centered description of care histories. A further strength is that our analysis was 
based on a large, representative sample and included those in all types of out-of-home care, not just foster care. Additionally, the choice of DHM as a method of assessing the similarity of sequences meant that no assumptions about the distribution of the empirical data or the relative importance of the number, timing and duration of placements were made. Instead, the subgroups of placement history that were identified were driven by the observed heterogeneity of the data. The choice of administrative data for this analysis was also a strength as this is a more accurate source of data for exploring the placement histories than survey- or interview-based studies which may be subject to error or recall bias when selfreported (Dregan \& Gulliford, 2012).

The main limitation of sequence analysis is that, because there is no underlying statistical model, it is not possible to determine the optimum number of clusters. However, the aim of this analysis was not to create a definitive classification of care histories based on placement stability. Rather, the aims were to describe the stability of care histories accounting for all placement changes, from birth to age 18 , and to explore whether there were distinct patterns of placement stability. The six subgroups of care histories we identified (although not definitive) are certainly a more nuanced description of care histories than the narrow indicators of stability typically used in DfE statistics (i.e., three or more placements in a 12-month period).

A further limitation of our sequence analysis is that the decisions to use months as the unit of time, to restrict the total number of placements to 14 , and to not account for the type of placement masked some information related to the stability of care histories among this cohort. For example, if a child was in more than one placement in a month, the timing and 
duration of placements within that month were not accurately recorded. Similarly, the duration of children's $14^{\text {th }}$ placements was artificially extended and any subsequent placements were not recorded; however, this issue affected a small proportion of the sample overall $(2.3 \%, n=368)$. We could have chosen a shorter time period of weeks or days, allowed for all placements to be counted and included placement type to create more accurate sequences; however, comparing these sequences would have created larger dissimilarity matrices and would have required us to reduce the sample size to carry out the analysis.

Studies from other countries have also used sequence analysis to explore differing patterns of placement stability using whole childhood records of placements in care. However, these studies have tended to be limited to subgroups of children (such as children who entered care before or after a certain age (Andersen, 2014) or children who were ageing out of the care system at age 18 (Havlicek, 2010)) which limits the ability to draw crossnational comparisons with our current study. However, one comparable study has applied the same methodology to a similar administrative dataset which included complete foster care histories for all children in Denmark who were born between 1982 and 1987 and ever entered out-of-home care (Fallesen, 2014).

Using DHM and clustering, Fallesen (2014) identified nine divergent foster care "careers", four of which were comparable to placement sequences that were identified in our analysis (though the relative sizes of the subgroups differed). In our English sample we identified one group with "stable $1^{\text {st }}$ placements" that accounted for just $1.6 \%$ of children whereas Fallesen identified three groups with differing ages at first entry that accounted for 13.7\% ( $n=4,133$ ) of children in Denmark. Similarly, Fallesen (2014) identified two groups of 
"stable $2^{\text {nd }}$ placements" that included $3.8 \%$ of children $(n=1,138)$ whereas this group accounted for $2.4 \%$ of children in our English sample. Among the Danish sample there were also two complex foster care careers that were similar to the "long-term complex care" group that we identified in this analysis. However, the Danish group had a longer duration of care (124.0 vs 103.9 months in our analysis) and fewer placements (3.6 vs 9.0). In total, just 5.3\% of children in Denmark had patterns of care that could be described as "Iong-term complex care" compared to $13.1 \%$ of children in our English sample. In both countries "shorter term care" was by far the dominant placement sequence, accounting for $77.3 \%$ of children in Denmark and $58.4 \%$ of children in our analysis.

Two of the patterns of care that we identified were unique to children in England: the "early intervention" and "adolescent $1^{\text {st }}$ entry". This may be due to differences in practice and policy related to out-of-home care between England and Denmark. For instance, the "early intervention" group we identified was composed of children who entered and left care before adolescence. However, children in Denmark tend to enter care for the first time at a later age than children in England (Ubbesen, Gilbert, \& Thoburn, 2015), perhaps because there is a greater emphasis on providing universal services that support parents in caring for children at home (Ploug, 2012). These differences in longitudinal placement histories between children in Denmark and England highlight the importance of developing country-specific typologies that account for variation in societal factors and social care practice.

Overall, when accounting for the number, timing, and duration of placements, as well as exits and re-entries to care, most children in our cohort of children in England appeared to have relatively stable care histories. For most children, placement in out-of-home care was a 
relatively short-term intervention (58.4\%). However, the Office of the Children's Commissioner for England has developed a stability index to quantify the occurrence of changes in placements, social workers and schools over a 12-month period for looked after children using administrative and survey data (Longfield, 2017). Although, $77 \%$ of children included in the 2018 Stability Index analysis had no placement changes in a year, more than half of these children (56\%) had changed social worker or moved school in that year (Children's Commissioner for England, 2018). Consequently, the relatively stable care histories in terms of placement changes that were observed in our analysis may mask instability in other aspects of children's lives. Further work is required to develop a set of holistic indicators that can be used to routinely monitor the stability of children's care experiences longitudinally.

The timeframe of our analysis (1992 to 2012) limits our ability to draw conclusions about current policies and practice that may influence placement stability for children in England. However, our analysis showed that some groups of children encountered high levels of placement change whilst in out-of-home care: one in eight (13.1\%) children had patterns of placement characterized by long-term complex care with an average of 9.0 placements throughout childhood, and a further one in six (17.6\%) did not enter care until adolescence and experienced 3.1 changes during this developmentally sensitive period. Indeed, only a small minority of children $(4.0 \%)$ appeared to experience stable, long-term $1^{\text {st }}$ or $2^{\text {nd }}$ placements and even among these children there was evidence of placements changing in adolescence. These findings highlight that some groups of looked after children experience high levels of placement change and so may require greater support to develop and maintain a sense of permanence. Numerous placement changes are likely to have an impact not only 
on children's relationships with caregivers, siblings, other family members, and friends, but also on their feelings of connection to their communities and opportunities to participate in typical childhood activities, such as having pets, maintaining hobbies, or taking part in sports (Beck, 2006; Fong, Schwab, \& Armour, 2006). These findings also re-enforce the value of collecting longitudinal data related to children's social care histories and of looking beyond the time frame of a single year when exploring the stability of children's care experiences.

Our analysis illustrates the utility and value of applying sequence analysis methods to administrative social care data to explore heterogeneous and complex care histories among children in England. We focused on placement changes as it is an established indicator of permanence; however, there is considerable scope for further applications of sequence analysis in this field. For example, future work could explore the utility of using sequence analysis to explore the stability of care histories over a shorter time frame for more recent cohorts of children or other aspects of care experiences, such as placement types, legal status, social worker changes and adoption pathways. Future work to explore the educational outcomes associated with different types of care history identified through sequence analysis would also be useful for identifying groups at higher likelihood of poor outcomes. This extended analysis was not possible for the cohort included in our study; however, for more recent cohorts of children who were born after 2005 it is possible to link the CLA dataset to national educational datasets. Sequence analysis of longitudinal care histories may also be a useful tool for evaluating the impact of policies introduced in recent years, such as Staying Put arrangements for children in foster care (HM Government, 2013). 


\section{References}

Abbot, A., \& Tsay, A. (2000). Sequence analysis and optimal matching methods in sociology. Sociological Methods \& Research, 29(1), 3-33.

Akister, J., Owens, M., \& Goodyer, I. M. (2010). Leaving care and mental health: Outcomes for children in out-of-home care during the transition to adulthood. Health Research Policy and Systems, 8(1), 10.

Andersen, S. H. (2014). Complex patterns: On the characteristics of children who experience high and low degrees of foster-care drift. British Journal of Social Work, 44, 1545-1562.

Beck, A. (2006). Addressing the mental health needs of looked after children who move placement frequently. Adoption \& Fostering, 30(3), 60-65.

Berridge, D., Luke, N., Sebba, J., Strand, S., Cartwright, M., Staples, E., Mc Grath-Lone, L., Ward, J., \& O'Higgins, A. (2020). Children in Need and children in care: Educational attainment and progress. Bristol, UK.

Boddy, J. (2013). Understanding permanence for Looked After Children: A review of reserach for the care inquiry. London, UK.

Children's Commissioner for England. (2018). Stability Index 2018: Technical report (pp. 6364). Retrieved from https://www.childrenscommissioner.gov.uk/wpcontent/uploads/2018/05/Childrens-Commissioners-2018-Stability-Index-TechnicalReport.pdf

Children's Commissioner for England. (2019). Stability Index 2019: Underlying data. 
Retrieved from https://www.childrenscommissioner.gov.uk/report/stability-index2019/

Department for Education. (2013). Improving permanence for Looked After Children. London, U.K.

Department for Education. (2015). The Children Act 1989 guidance and regulations Volume 2: Care planning, placement and case review. London, U.K.

Department for Education. (2016). Special guardianship guidance (Vol. 2005). London, U.K.

Department for Education. (2019). Children looked after in England (including adoption) year ending 31 March 2019: National tables (A2).

Department for Education. (2020). Children looked after by local authorities in England: Guide to the SSDA903 collection 1 April 2019 to 31 March 2020.

Dickson, K., Sutcliffe, K., \& Gough, D. (2010). What outcomes matter to Looked After children and young people and their families and carers? A systematic review of their experiences, views and preferences.

Dregan, A., \& Gulliford, M. C. (2012). Foster care, residential care and public care placement patterns are associated with adult life trajectories: Population-based cohort study. Social Psychiatry and Psychiatric Epidemiology, 47(9), 1517-1526.

Elder, G. H. (2016). The life course as developmental theory. The Life Course, 69(1), 1-12.

Fallesen, P. (2014). Identifying divergent foster care careers for Danish children. Child Abuse 
\& Neglect, 38(11), 1860-1871.

Fong, R., Schwab, J., \& Armour, M. (2006). Continuity of activities and child well-being for foster care youth. Children and Youth Services Review, 28(11), 1359-1374.

Halpin, B. (2012). Sequence analysis of life-course data: A comparison of distance measures. University of Limerick Department of Sociology Working Paper WP2012-02.

Havlicek, J. (2010). Patterns of movement in foster care: An optimal matching analysis. Social Service Review, (September).

HM Government (2013) Staying put: Arrangements for care leavers aged 18 and above to stay on with their former foster carers. DfE, DWP and HMRC guidance. Report number: DFE-00061-2013.

Jones, R., Everson-Hock, E. S., Papaioannou, D., Guillaume, L., Goyder, E., Chilcott, J., ... Swann, C. (2011). Factors associated with outcomes for looked-after children and young people: A correlates review of the literature. Child: Care, Health and Development, 37(5), 613-622.

Lesnard, L. (2010). Setting cost in optimal matching to uncover contemporaneous sociotemporal patterns. Sociological Methods \& Research (Vol. 38).

Longfield, A. (2017). The importance of stability for children in care: An overview of the Stability Index and its initial findings, (April), 1-11.

Mc Grath-Lone, L., Dearden, L., Nasim, B., Harron, K., \& Gilbert, R. (2016) Changes in first entry to out-of-home care form 1992 to 2012 among children in England. Child Abuse \& 
Neglect, 51(1), 163-171.

Mc Grath-Lone, L., Harron, K., Dearden, L., Nasim, B., \& Gilbert, R. (2016) Data resource profile: Children Looked After Return (CLA). International Journal of Epidemiology, 45(3), 716-717f.

Mc Grath-Lone, L., Harron, K., Dearden, L., Nasim, B., \& Gilbert, R. (2017). Factors associated with re-entry to out-of-home care among children in England. Child Abuse \& Neglect, 63(1), , 73-83.

Milligan, G., \& Cooper, M. (1985). An examination of procedures for determining the number of clusters in a data set. Psychometrika, 50(2), 159-179.

Neil, E., Gitsels, L., \& Thoburn, J. (2019). Children in care: Where do children entering care at different ages end up? An analysis of local authority administrative data. Children and Youth Services Review, 106. https://doi.org/10.1016/j.childyouth.2019.104472

O’Sullivan, A., \& Westerman, R. (2007). Closing the Gap: Investigating the barriers to educational achievement for Looked after Children. Adoption \& Fostering, 31(1), 1320.

Panchamia, N., \& Thomas, P. (2017). Public Service Agreements and the Prime Minister's Delivery Unit.

Ploug, N. (2012). The Nordic child care regime - History, development and challenges. Child and Youth Service Review, 34(3), 517-522. 
Ranson, K. E., \& Urichuk, L. J. (2008). The effect of parent-child attachment relationships on child biopsychosocial outcomes: A review. Early Child Development and Care, 178(2), 129-152.

Richardson, J., \& Lelliott, P. (2003). Mental health of looked after children. Advances in Psychiatric Treatment, 9, 249-251.

Schofield, G., Thoburn, J., Howell, D., \& Dickens, J. (2007). The search for stability and permanence: Modelling the pathways of long-stay looked after children. British Journal of Social Work, 37(4), 619-642.

Sebba, J., Berridge, D., Luke, N., Fletcher, J., Bell, K., Strand, S., Thomas, S., Sinclair, I., \& O'Higggins, A. (2015). The eEducational progress of Looked After Children in England: Linking care and educational data. Oxford, UK.

Selwyn, J., Wood, M., \& Newman, T. (2017). Looked After children and young people in England: Developing measures of subjective well-being. Child Indicators Research, 10, $363-380$.

Sinclair, I., Baker, C., Lee, J., \& Gibbs, I. (2007). The pursuit of permanence: A study of the English child care system. (M. Stein \& C. Thomas, Eds.). London: Jessica Kingsley Publishers.

Stanley, N., Riordan, D., \& Alaszewski, H. (2005). The mental health of looked after children: Matching response to need. Health and Social Care in the Community, 13(3), 239-248.

Thomas, C. (2013). Adoption for Looked After Children: Messages from research. London, 
U.K.

Ubbesen, M.-B., Gilbert, R., \& Thoburn, J. (2015). Cumulative incidence of entry into out-ofhome care: Changes over time in Denmark and England. Child Abuse \& Neglect, 42, 6371. 


\begin{tabular}{|c|c|c|c|c|c|c|c|c|c|c|c|c|}
\hline & \multicolumn{12}{|c|}{ Month } \\
\hline & 1 & 2 & 3 & 4 & 5 & 6 & 7 & 8 & 9 & 10 & 11 & 12 \\
\hline Child A & P1 & $\mathrm{P} 1$ & $\begin{array}{c}\text { Not in } \\
\text { care }\end{array}$ & $\begin{array}{c}\text { Not in } \\
\text { care }\end{array}$ & $\begin{array}{c}\text { Not in } \\
\text { care }\end{array}$ & $\begin{array}{l}\text { Not in } \\
\text { care }\end{array}$ & $\begin{array}{c}\text { Not in } \\
\text { care }\end{array}$ & $\begin{array}{l}\text { Not in } \\
\text { care }\end{array}$ & $\begin{array}{c}\text { Not in } \\
\text { care }\end{array}$ & $\begin{array}{c}\text { Not in } \\
\text { care }\end{array}$ & $\begin{array}{c}\text { Not in } \\
\text { care }\end{array}$ & $\begin{array}{c}\text { Not in } \\
\text { care }\end{array}$ \\
\hline Child B & P1 & P1 & $\begin{array}{l}\text { Not in } \\
\text { care }\end{array}$ & $\begin{array}{l}\text { Not in } \\
\text { care }\end{array}$ & $\begin{array}{l}\text { Not in } \\
\text { care }\end{array}$ & $\begin{array}{l}\text { Not in } \\
\text { care }\end{array}$ & $\begin{array}{c}\text { Not in } \\
\text { care }\end{array}$ & $\begin{array}{l}\text { Not in } \\
\text { care }\end{array}$ & $\begin{array}{c}\text { Not in } \\
\text { care }\end{array}$ & $\begin{array}{c}\text { Not in } \\
\text { care }\end{array}$ & $\begin{array}{c}\text { Not in } \\
\text { care }\end{array}$ & P2 \\
\hline Child C & P1 & $\mathrm{P} 1$ & P2 & P2 & P2 & P2 & $\begin{array}{c}\text { Not in } \\
\text { care }\end{array}$ & $\begin{array}{l}\text { Not in } \\
\text { care }\end{array}$ & $\begin{array}{c}\text { Not in } \\
\text { care }\end{array}$ & $\begin{array}{c}\text { Not in } \\
\text { care }\end{array}$ & $\begin{array}{l}\text { Not in } \\
\text { care }\end{array}$ & $\begin{array}{c}\text { Not in } \\
\text { care }\end{array}$ \\
\hline Child D & $\mathrm{P} 1$ & P1 & P2 & P2 & P2 & $\mathrm{P} 2$ & $\mathrm{P} 2$ & P2 & P2 & P2 & P2 & $\begin{array}{l}\text { Not in } \\
\text { care }\end{array}$ \\
\hline Child E & $\begin{array}{l}\text { Not in } \\
\text { care }\end{array}$ & $\begin{array}{c}\text { Not in } \\
\text { care }\end{array}$ & P2 & P2 & P2 & P2 & P2 & P2 & P2 & P2 & P2 & P2 \\
\hline Child F & $\begin{array}{l}\text { Not in } \\
\text { care }\end{array}$ & $\begin{array}{c}\text { Not in } \\
\text { care }\end{array}$ & $\begin{array}{l}\text { Not in } \\
\text { care }\end{array}$ & P2 & P2 & P2 & P2 & P4 & P5 & P5 & P5 & P5 \\
\hline Child G & $\begin{array}{l}\text { Not in } \\
\text { care }\end{array}$ & $\begin{array}{c}\text { Not in } \\
\text { care }\end{array}$ & $\mathrm{P} 1$ & $\mathrm{P} 1$ & P1 & P1 & $\mathrm{P} 1$ & P1 & $\mathrm{P} 1$ & P2 & P2 & P2 \\
\hline Child H & P1 & $\mathrm{P} 1$ & $\mathrm{P} 1$ & $\mathrm{P} 1$ & $\mathrm{P} 1$ & $\mathrm{P} 1$ & $\mathrm{P} 1$ & P1 & P1 & $\begin{array}{l}\text { Not in } \\
\text { care }\end{array}$ & $\begin{array}{l}\text { Not in } \\
\text { care }\end{array}$ & $\begin{array}{c}\text { Not in } \\
\text { care }\end{array}$ \\
\hline Child I & $\begin{array}{l}\text { Not in } \\
\text { care }\end{array}$ & $\begin{array}{c}\text { Not in } \\
\text { care }\end{array}$ & $\begin{array}{l}\text { Not in } \\
\text { care }\end{array}$ & $\begin{array}{l}\text { Not in } \\
\text { care }\end{array}$ & $\begin{array}{l}\text { Not in } \\
\text { care }\end{array}$ & $\begin{array}{l}\text { Not in } \\
\text { care }\end{array}$ & $\begin{array}{c}\text { Not in } \\
\text { care }\end{array}$ & $\begin{array}{l}\text { Not in } \\
\text { care }\end{array}$ & $\begin{array}{c}\text { Not in } \\
\text { care }\end{array}$ & $\begin{array}{l}\text { Not in } \\
\text { care }\end{array}$ & $\begin{array}{l}\text { Not in } \\
\text { care }\end{array}$ & $\begin{array}{c}\text { Not in } \\
\text { care }\end{array}$ \\
\hline Child J & P1 & P1 & $\begin{array}{l}\text { Not in } \\
\text { care }\end{array}$ & $\begin{array}{l}\text { Not in } \\
\text { care }\end{array}$ & $\begin{array}{l}\text { Not in } \\
\text { care }\end{array}$ & $\begin{array}{l}\text { Not in } \\
\text { care }\end{array}$ & $\begin{array}{c}\text { Not in } \\
\text { care }\end{array}$ & $\begin{array}{l}\text { Not in } \\
\text { care }\end{array}$ & $\begin{array}{l}\text { Not in } \\
\text { care }\end{array}$ & $\begin{array}{l}\text { Not in } \\
\text { care }\end{array}$ & $\begin{array}{l}\text { Not in } \\
\text { care }\end{array}$ & $\begin{array}{c}\text { Not in } \\
\text { care }\end{array}$ \\
\hline
\end{tabular}

\section{Figure 1}

Examples of out-of-home care placement sequences for 1 year of childhood 
$\mathrm{P}=$ placement. Figure 1 illustrates the sequence of placements over 1 year of childhood comprised of 12 "state" variables for each month. Examples $E$ and $F$ illustrates the limitation of using month as a unit of time. Child $E$ first entered care in month 3 and, during this month, they moved from their $1^{\text {st }}$ to their $2^{\text {nd }}$ placement. However, the exact timing and duration of these placements are not captured by this sequence. Similarly, Child F first entered care in month 4 and, during this month, they moved from their $1^{\text {st }}$ to their $2^{\text {nd }}$ placement. In month 8 , they moved from their $2^{\text {nd }}$ to $3^{\text {rd }}$ placement and from their $3^{\text {rd }}$ to $4^{\text {th }}$ placement. However, the exact timing and duration of these placements are not captured by this sequence. 


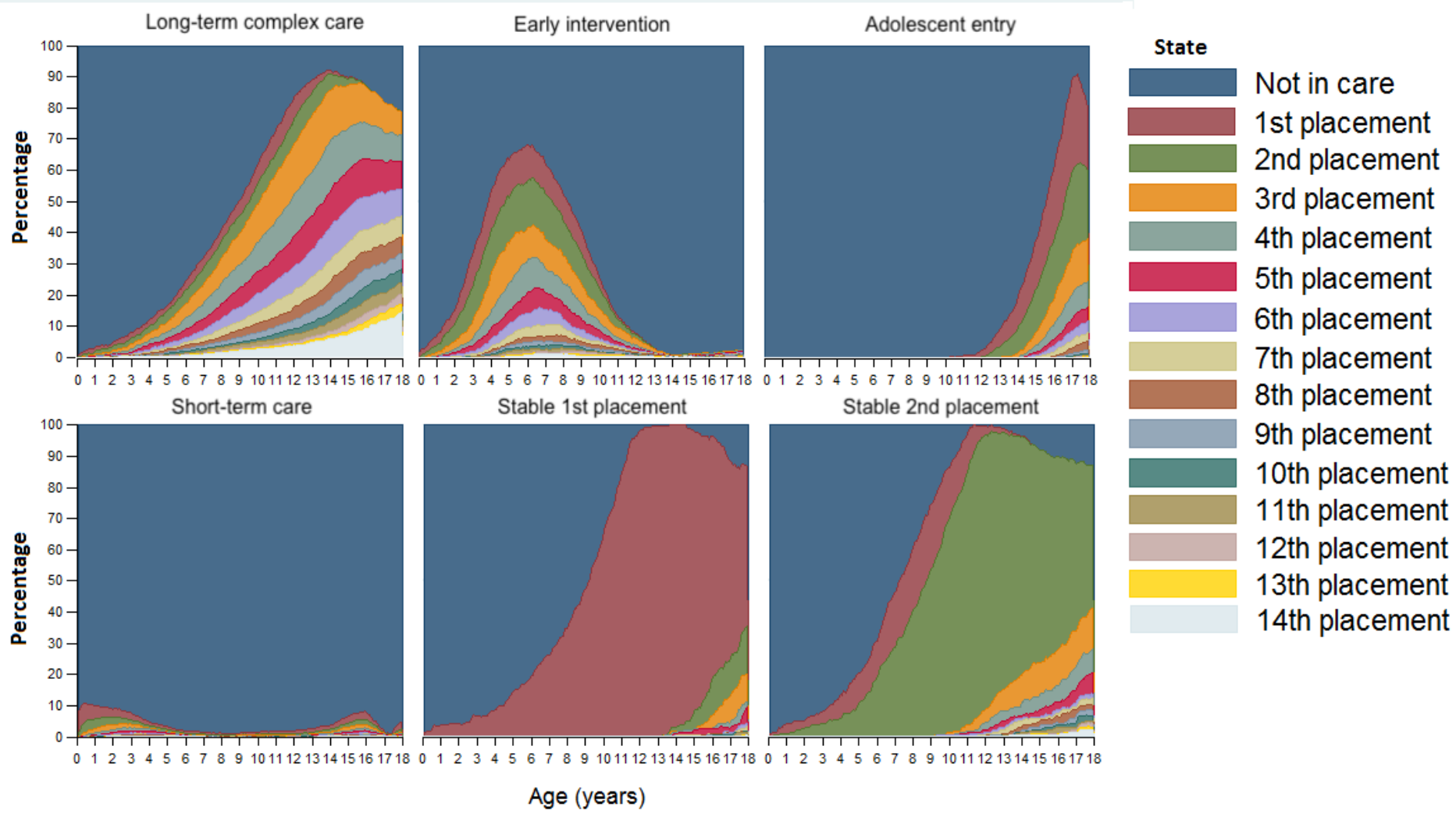

\section{Figure 2}

Chronograms of the placement sequences, by cluster $(N=16,000)$

Figure 2 illustrates the percentage of children within a cluster in a particular state throughout childhood. $N$ for each cluster is given in Table 2. As previously described, $15^{\text {th }}$ and subsequent placements were coded as $14^{\text {th }}$ placement to reduce the complexity of the sequences for $2.3 \%$ of children $(n=368)$. 


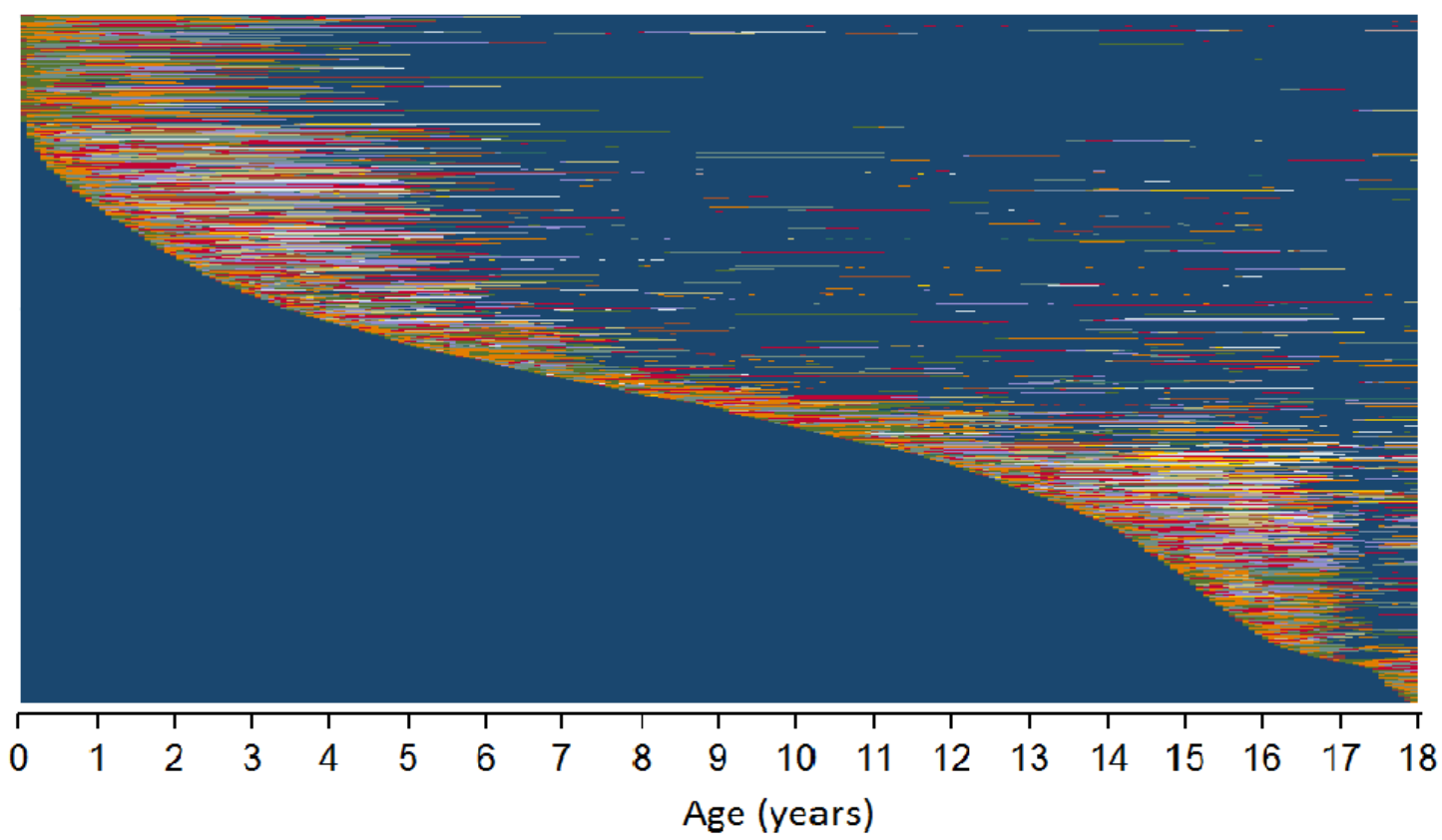

Figure 3

Sequence index plot for "Shorter term care" subgroup (58.4\%)

$n=9,345$. Each horizontal line represents an individual's sequence of placements throughout childhood. Placements are color coded as per the legend in Figure 2. 


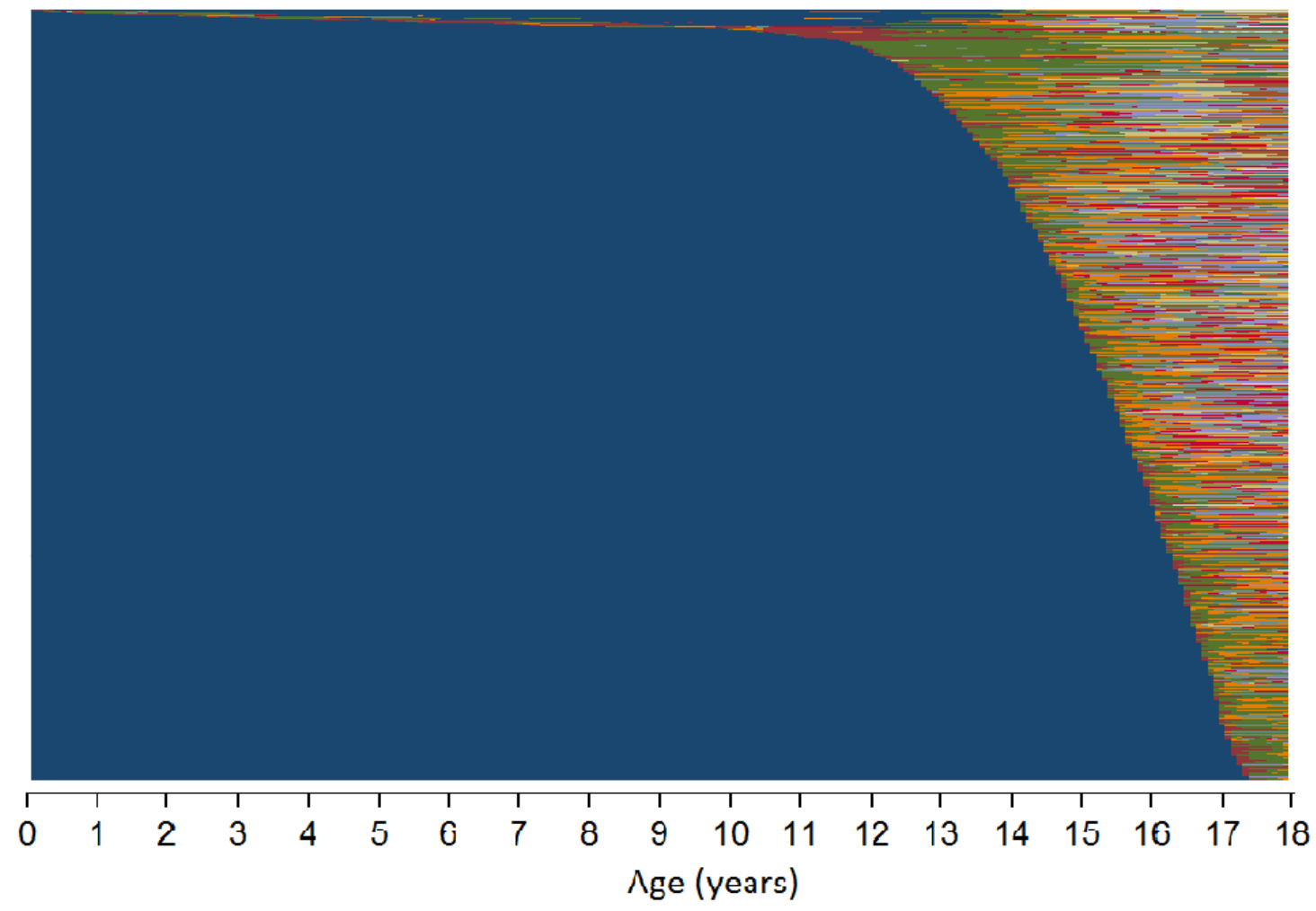

Figure 4

Sequence index plot for "Adolescent $1^{\text {st }}$ entry" subgroup (17.6\%)

$n=2,821$. Each horizontal line represents an individual's sequence of placements throughout childhood. Placements are color coded as per the legend in Figure 2. 


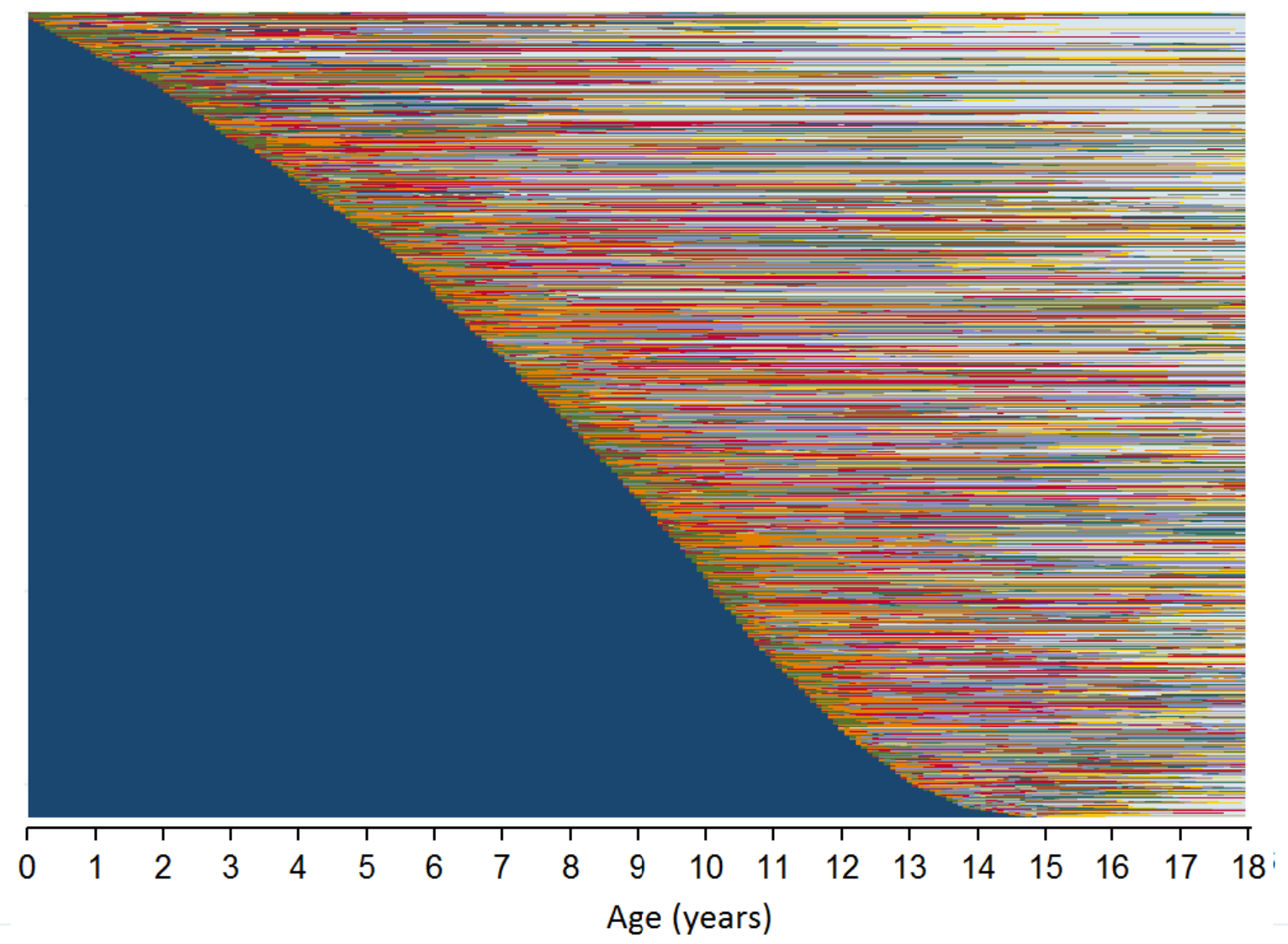

\section{Figure 5}

Sequence index plot for "Long-term complex care" subgroup (13.1\%)

$n=2,093$. Each horizontal line represents an individual's sequence of placements throughout childhood. Placements are color coded as per the legend in Figure 2. 


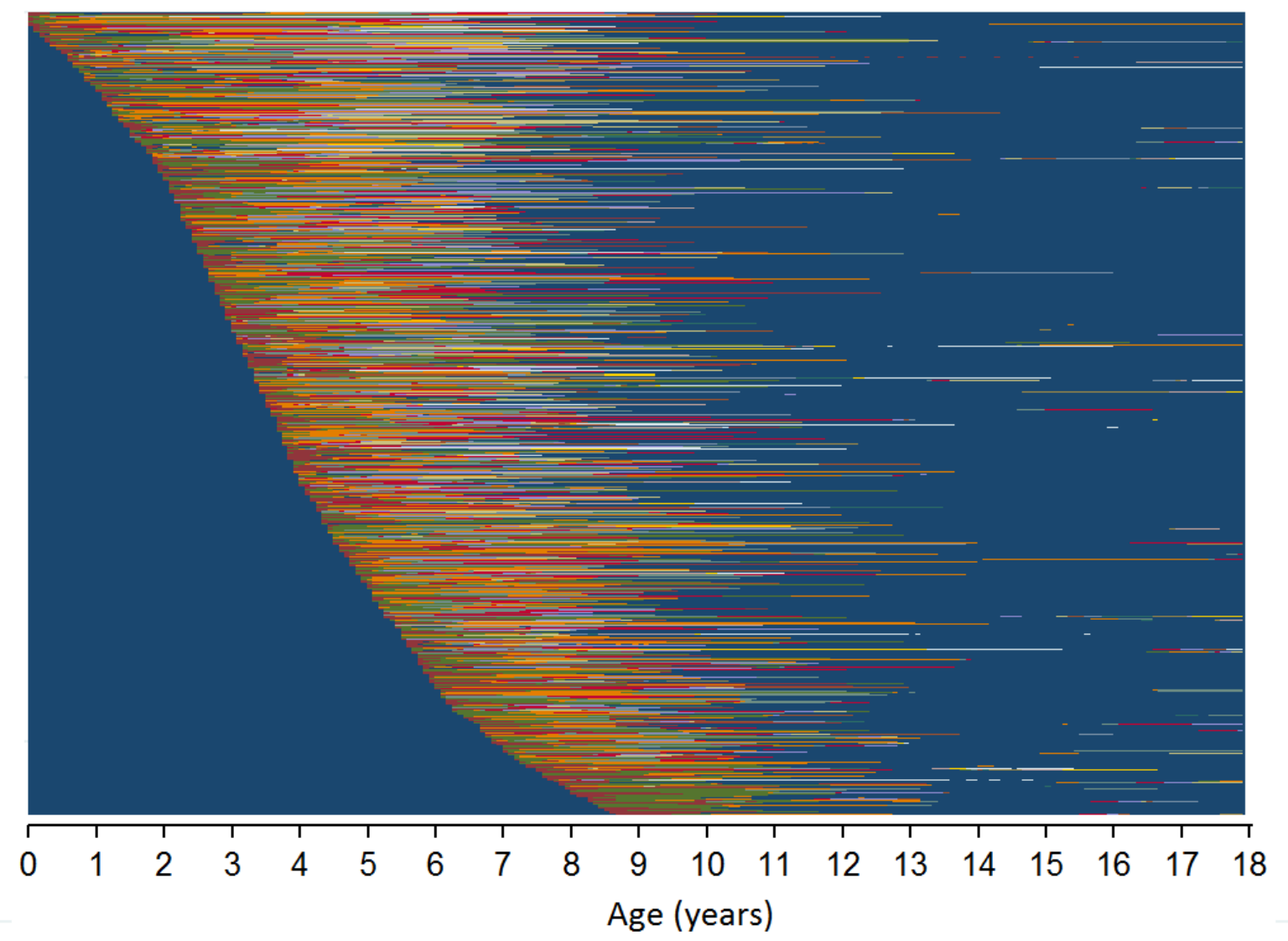

\section{Figure 6}

Sequence index plot for "Early intervention" subgroup (6.9\%)

$n=1,105$. Each horizontal line represents an individual's sequence of placements throughout childhood. Placements are color coded as per the legend in Figure 2. 


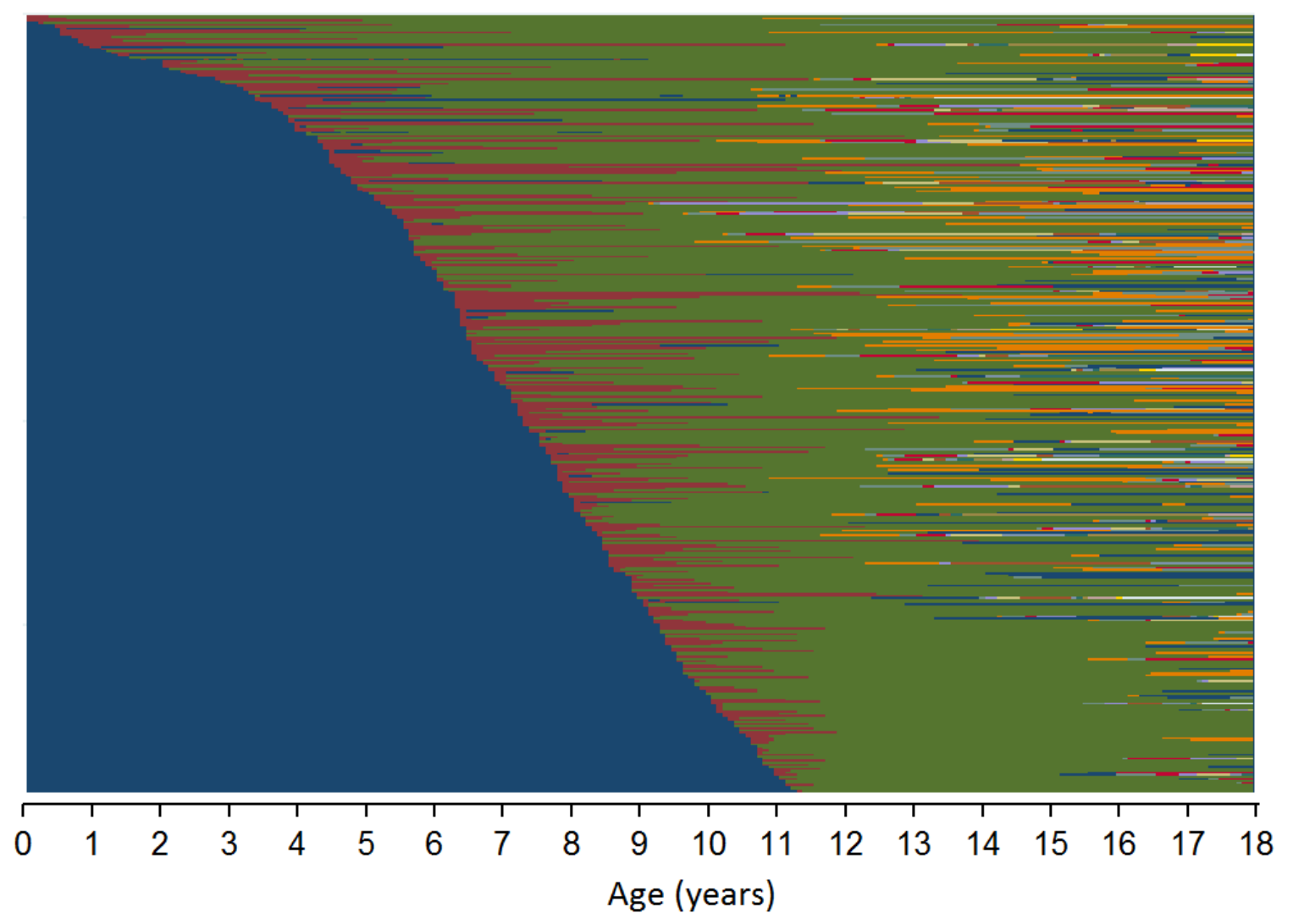

Figure 7

Sequence index plot for "Stable $2^{\text {nd }}$ placement" subgroup (2.4\%)

$n=382$. Each horizontal line represents an individual's sequence of placements throughout childhood. Placements are color coded as per the legend in Figure 2 


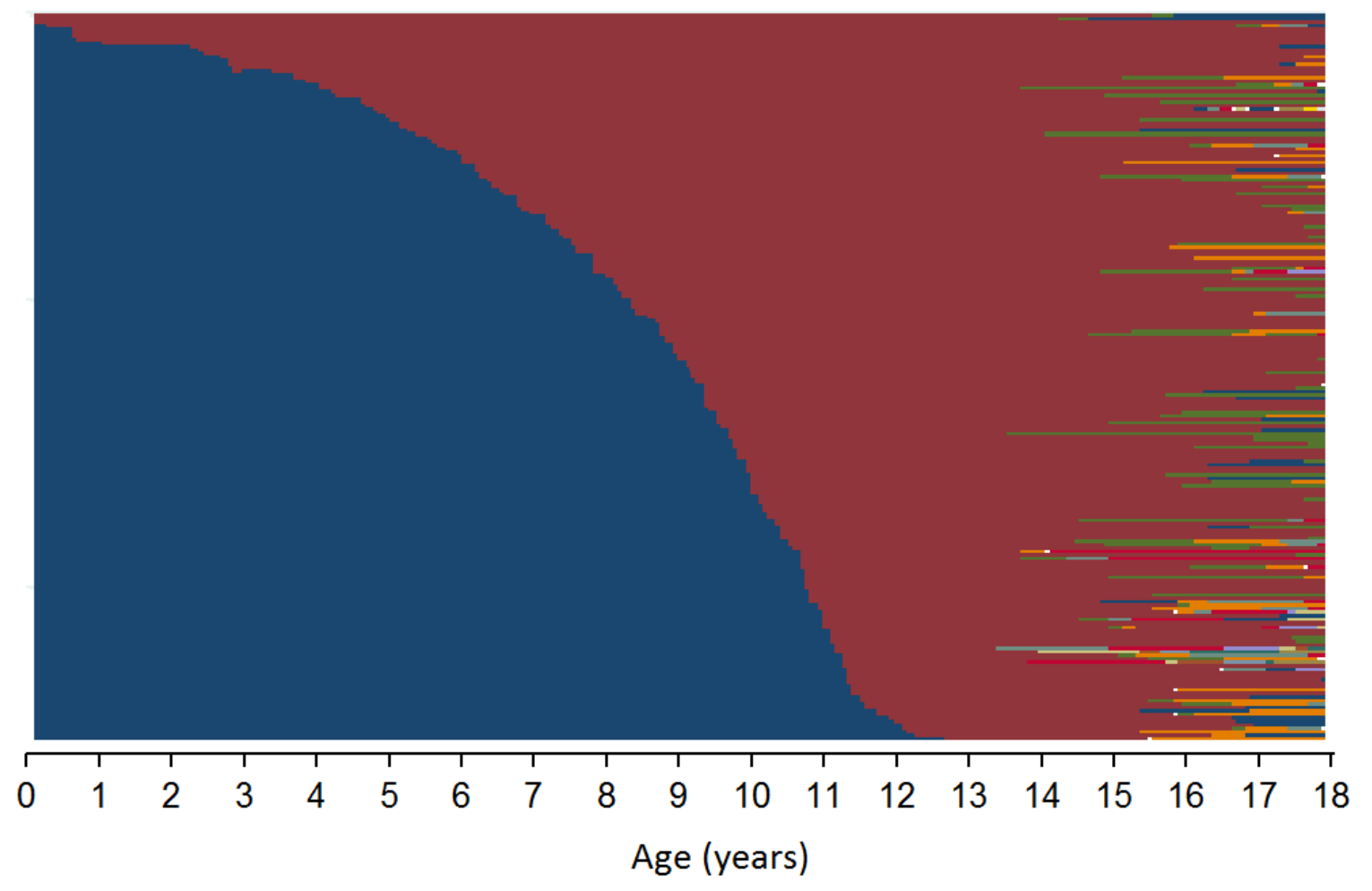

Figure 8

Sequence index plot for "Stable $1^{\text {st }}$ placement" subgroup (1.6\%)

$n=254$. Each horizontal line represents an individual's sequence of placements throughout childhood. Placements are color coded as per the legend in Figure 2. 
Table 1

Demographic and selected care history characteristics of sample $(N=16,000)$

\begin{tabular}{|c|c|c|c|c|c|}
\hline Sex & $n$ & $\%$ & $\begin{array}{l}\text { Age group at first } \\
\text { entry to care (years) }\end{array}$ & $n$ & $\%$ \\
\hline Male & 8,701 & 54.4 & $<1$ & 2,353 & 14.7 \\
\hline \multirow[t]{2}{*}{ Female } & 7,229 & 45.2 & 1 to 4 & 3,517 & 22.0 \\
\hline & & & 5 to 10 & 3,539 & 22.1 \\
\hline Ethnic category ${ }^{a}$ & $n$ & $\%$ & 11 to 15 & 4,819 & 30.1 \\
\hline White & 8,444 & 52.8 & $16+$ & 1,772 & 11.1 \\
\hline Black & 1,068 & 6.7 & & & \\
\hline Mixed & 771 & 4.8 & Legal basis for first & & \\
\hline Asian & 836 & 5.2 & entry to care ${ }^{b}$ & $n$ & $\%$ \\
\hline Other & 527 & 3.3 & Voluntary & 11,717 & 73.2 \\
\hline \multirow[t]{2}{*}{ Unknown } & 4,354 & 27.2 & Child protection & 2,098 & 13.1 \\
\hline & & & Other compulsory & 2,185 & 13.7 \\
\hline Total placements changes & $n$ & $\%$ & & & \\
\hline $0 / 1$ changes & 8,690 & 54.3 & Total time in care & $n$ & $\%$ \\
\hline $2 / 3$ changes & 3,365 & 21.0 & $<1$ month & 3,107 & 19.5 \\
\hline 4-6 changes & 2,170 & 13.6 & 1 to 12 months & 4,227 & 26.4 \\
\hline 7-9 changes & 906 & 5.7 & 1 to 5 years & 5,674 & 35.5 \\
\hline $10+$ changes & 869 & 5.4 & $5+$ years & 2,992 & 18.7 \\
\hline Mean & \multicolumn{2}{|c|}{2.6 changes } & Mean & \multicolumn{2}{|c|}{32 months } \\
\hline Median & \multicolumn{2}{|c|}{1 change } & Median & \multicolumn{2}{|c|}{15 months } \\
\hline Total re-entries to care & $n$ & $\%$ & Age group at final & & \\
\hline No re-entries & 10,722 & 67.0 & exit from care (years) & $n$ & $\%$ \\
\hline 1 re-entry & 3,168 & 19.8 & $<1$ & 845 & 5.3 \\
\hline \multirow[t]{4}{*}{$>1$ re-entry } & 2,110 & 13.2 & 1 to 4 & 2,638 & 16.5 \\
\hline & & & 5 to 10 & 2,553 & 16.0 \\
\hline & & & 11 to 15 & 2,591 & 16.2 \\
\hline & & & $16+$ & 7,373 & 46.1 \\
\hline \multicolumn{6}{|c|}{$\begin{array}{l}\text { Other ethnicity includes Chinese, as per the categories used in official statistics related to } \\
\text { looked after children in England (Department for Education, 2017). Ethnicity has been } \\
\text { collected in the Children Looked After Return (CLA) from } 1^{\text {st }} \text { April, 2000. Children who were } \\
\text { only in care before this date could not have ethnicity recorded in the CLA dataset and so } \\
\text { ethnicity is Unknown for } 27.2 \% .{ }^{b} \text { Child protection includes children entering care through } \\
\text { police protective powers and child assessment and emergency protection orders. All other } \\
\text { compulsory entries to care are included in Other compulsory (e.g., care and supervision } \\
\text { orders). }\end{array}$} \\
\hline
\end{tabular}


Table 2

Frequency and characteristics of subgroups of care placement stability

\begin{tabular}{|c|c|c|c|c|c|c|}
\hline Subgroup & $\begin{array}{l}\text { Long-term } \\
\text { complex care }\end{array}$ & $\begin{array}{c}\text { Early } \\
\text { intervention }\end{array}$ & $\begin{array}{c}\text { Adolescent } \\
1^{\text {st }} \text { entry }\end{array}$ & $\begin{array}{c}\text { Shorter } \\
\text { term care }\end{array}$ & $\begin{array}{l}\text { Stable } 1^{\text {st }} \\
\text { placement }\end{array}$ & $\begin{array}{l}\text { Stable } 2^{\text {nd }} \\
\text { placement }\end{array}$ \\
\hline $\mathrm{N}$ & 2,093 & 1,105 & 2,821 & 9,345 & 254 & 382 \\
\hline$\%$ of sample ${ }^{a}$ & $13.1 \%$ & $6.9 \%$ & $17.6 \%$ & $58.4 \%$ & $1.6 \%$ & $2.4 \%$ \\
\hline \multicolumn{7}{|c|}{ Age at first entry to care (years) } \\
\hline Range & 0 to 15 & 0 to 8 & 0 to 17 & 0 to 17 & 0 to 12 & 0 to 11 \\
\hline Mean & 6.58 & 3.12 & 14.05 & 7.23 & 7.41 & 6.08 \\
\hline Median & 7 & 3 & 15 & 6 & 8 & 6 \\
\hline \multicolumn{7}{|c|}{ Legal status of first entry ${ }^{b}$} \\
\hline Voluntary & $61.1 \%$ & $57.5 \%$ & $86.8 \%$ & $74.8 \%$ & $67.3 \%$ & $51.0 \%$ \\
\hline Child protection & $18.1 \%$ & $18.2 \%$ & $4.5 \%$ & $13.9 \%$ & $6.3 \%$ & $19.4 \%$ \\
\hline Other compulsory & $20.8 \%$ & $24.3 \%$ & $8.6 \%$ & $11.3 \%$ & $26.4 \%$ & $29.6 \%$ \\
\hline \multicolumn{7}{|c|}{ Total time in care (months) ${ }^{\mathrm{c}}$} \\
\hline Mean & 103.9 & 52.9 & 29.8 & 8.9 & 105.9 & 123.2 \\
\hline Median & 101 & 49 & 27 & 4 & 102 & 120 \\
\hline \multicolumn{7}{|l|}{ Ever re-enter care? } \\
\hline Yes & $58.3 \%$ & $43.7 \%$ & $23.6 \%$ & $29.8 \%$ & $9.8 \%$ & $25.1 \%$ \\
\hline No & $41.7 \%$ & $56.3 \%$ & $76.4 \%$ & $70.2 \%$ & $90.2 \%$ & $74.9 \%$ \\
\hline \multicolumn{7}{|c|}{ Total number of placements } \\
\hline Range & 1 to 184 & 1 to 59 & 1 to 21 & 1 to 119 & 1 to 15 & 2 to 26 \\
\hline Mean & 9.0 & 5.0 & 3.1 & 2.5 & 2.0 & 3.9 \\
\hline Median & 7 & 4 & 2 & 2 & 1 & 3 \\
\hline \multicolumn{7}{|l|}{ Ever placed in... } \\
\hline Foster care & $97.6 \%$ & $99.1 \%$ & $65.2 \%$ & $85.8 \%$ & $81.9 \%$ & $97.6 \%$ \\
\hline Kin foster care ${ }^{d}$ & $37.6 \%$ & $42.6 \%$ & $15.5 \%$ & $18.9 \%$ & $31.7 \%$ & $36.7 \%$ \\
\hline Respite care ${ }^{\mathrm{e}}$ & $10.8 \%$ & $10.6 \%$ & $8.2 \%$ & $6.4 \%$ & $18.9 \%$ & $9.7 \%$ \\
\hline \multicolumn{7}{|c|}{ Age at final exit from care (years) } \\
\hline Range & 11 to 18 & 4 to 18 & 15 to 18 & 0 to 18 & 14 to 18 & 12 to 18 \\
\hline Mean & 17.5 & 8.8 & 17.7 & 8.7 & 17.8 & 17.7 \\
\hline Median & 18 & 8 & 18 & 8 & 18 & 18 \\
\hline \multicolumn{7}{|c|}{ 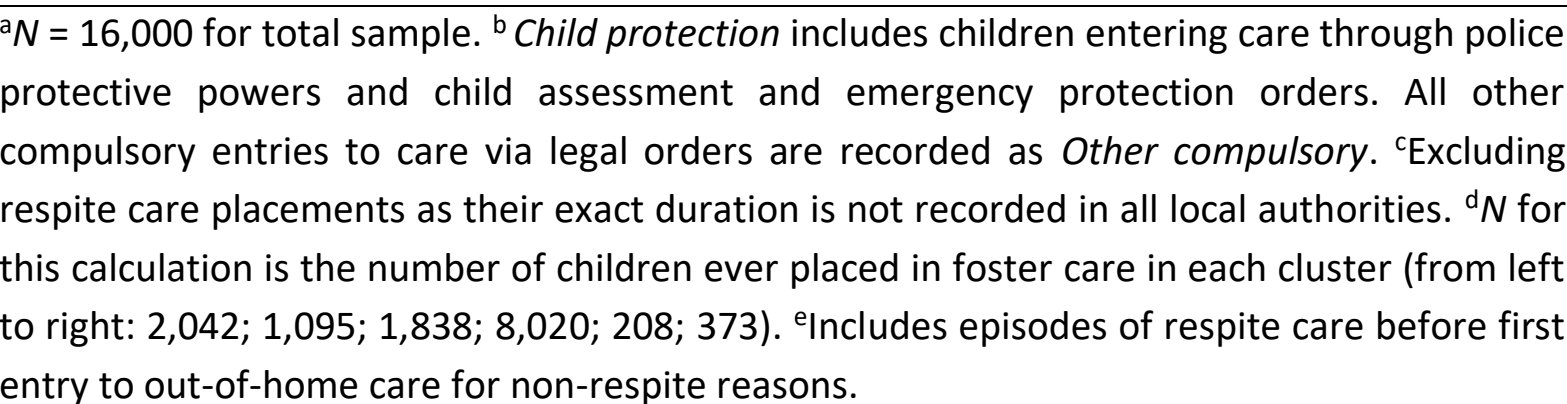 } \\
\hline
\end{tabular}




\section{Supplementary Table 1}

Comparison of demographic and selected care characteristics for the full cohort of children born between 1992 and 1994 who entered out-of-home care and the randomly selected sub-sample

\begin{tabular}{|c|c|c|c|c|c|c|}
\hline & & \multicolumn{2}{|c|}{$\begin{array}{l}\text { Full cohort } \\
(N=19,848)\end{array}$} & \multicolumn{2}{|c|}{$\begin{array}{l}\text { Sub-sample } \\
(n=16,000)\end{array}$} & \multirow[b]{2}{*}{ p-value } \\
\hline & & $\mathbf{n}$ & $\%$ & $\mathbf{n}$ & $\%$ & \\
\hline \multirow[t]{2}{*}{ Sex } & Male & 10,783 & 54.3 & 8,701 & 54.4 & \\
\hline & Female & 9,065 & 45.7 & 7,229 & 45.2 & 0.76 \\
\hline \multirow[t]{6}{*}{ Ethnicity } & White & 10,477 & 52.8 & 8,444 & 52.8 & \\
\hline & Mixed & 955 & 4.8 & 771 & 4.8 & \\
\hline & Asian & 1,019 & 5.1 & 836 & 5.2 & \\
\hline & Black & 1,339 & 6.8 & 1,068 & 6.7 & \\
\hline & Other & 646 & 3.3 & 527 & 3.3 & \\
\hline & Missing & 5,412 & 27.3 & 4,354 & 27.2 & 0.99 \\
\hline Age group at first & $<1$ year & 2,941 & 14.8 & 2,353 & 14.7 & \\
\hline \multirow[t]{4}{*}{ entry to care } & 1 to 4 years & 4,342 & 21.9 & 3,517 & 22.0 & \\
\hline & 5 to 10 years & 4,374 & 22.0 & 3,539 & 22.1 & \\
\hline & 11 to 15 years & 6,013 & 30.3 & 4,819 & 30.1 & \\
\hline & $16+$ years & 2,178 & 11.0 & 1,772 & 11.1 & 0.54 \\
\hline Legal basis for first & Voluntary & 14,530 & 73.2 & 11,717 & 73.2 & \\
\hline \multirow[t]{2}{*}{ entry to care ${ }^{b}$} & Child protection & 2,568 & 12.9 & 2,098 & 13.1 & \\
\hline & Other compulsory & 2,750 & 13.9 & 2,185 & 13.7 & 0.79 \\
\hline \multirow[t]{2}{*}{ Total time spent in } & Mean & \multicolumn{2}{|c|}{2 years, 8 months } & \multicolumn{2}{|c|}{2 years, 8 months } & \\
\hline & Median & \multicolumn{2}{|c|}{1 year, 3 months } & \multicolumn{2}{|c|}{1 year, 3 months } & 0.93 \\
\hline \multirow[t]{2}{*}{ Total placement } & Mean & \multicolumn{2}{|c|}{2.6 changes } & \multicolumn{2}{|c|}{2.6 changes } & \\
\hline & Median & \multicolumn{2}{|c|}{1 change } & \multicolumn{2}{|c|}{1 change } & 0.95 \\
\hline Total re-entries to & No re-entries & 13,335 & 67.2 & 10,722 & 67.0 & \\
\hline \multirow[t]{2}{*}{ care } & 1 re-entry & 3,910 & 19.7 & 3,168 & 19.8 & \\
\hline & $>1$ re-entry & 2,603 & 13.1 & 2,110 & 13.2 & 0.46 \\
\hline Age group at first & $<1$ year & 1,062 & 5.4 & 845 & 5.3 & \\
\hline \multirow[t]{4}{*}{ entry to care } & 1 to 4 years & 3,284 & 16.6 & 2,638 & 16.5 & \\
\hline & 5 to 10 years & 3,151 & 15.9 & 2,553 & 16.0 & \\
\hline & 11 to 15 years & 3,223 & 16.2 & 2,591 & 16.2 & \\
\hline & $16+$ years & 9,128 & 46.0 & 7,373 & 46.1 & 0.99 \\
\hline
\end{tabular}

Significant differences between the overall cohort and analysis sub-sample were tested for using $\chi^{2}$ tests for categorical variables and t-tests for continuous variables. 


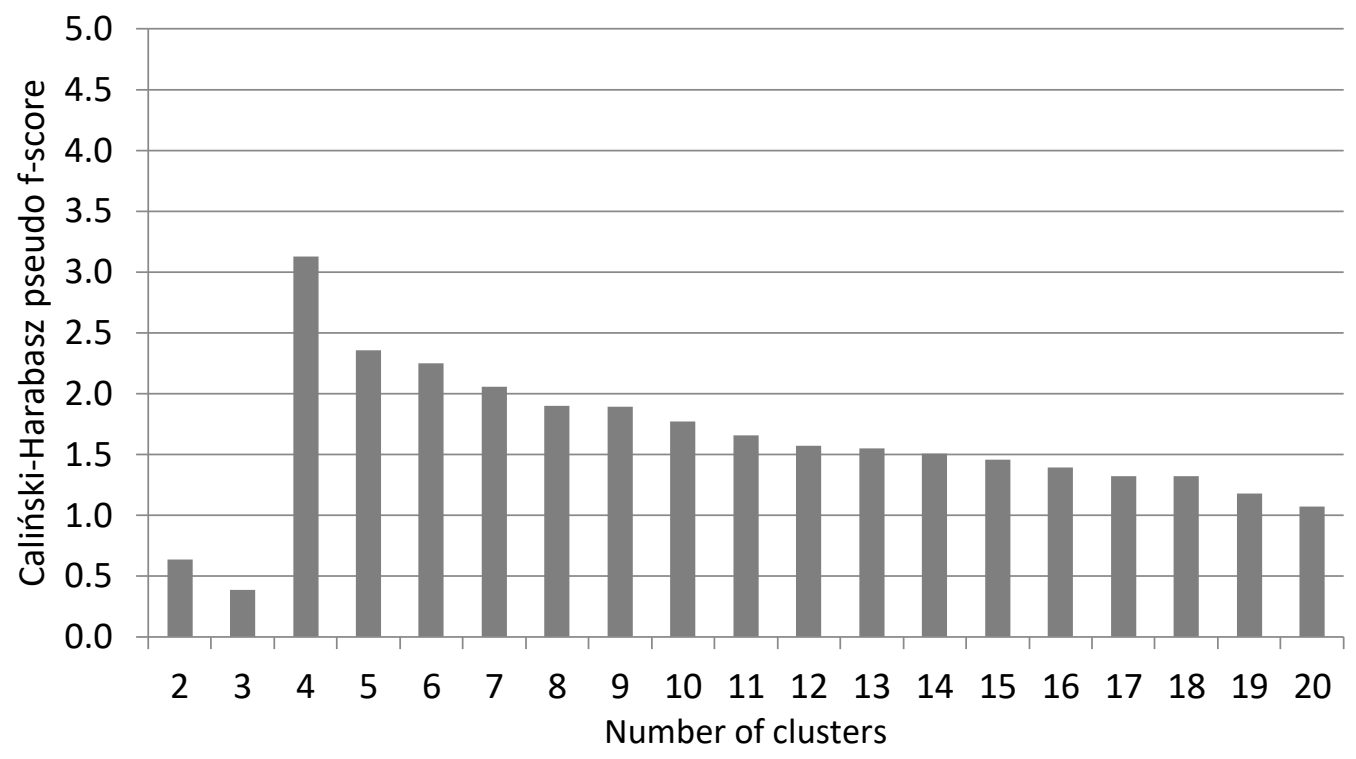

\section{Supplementary Figure 1}

Distribution of the Caliński-Harabasz pseudo f-score for solutions with two to twenty clusters using Ward's algorithm

We tested solutions with up to twenty clusters in this analysis. We chose the six-cluster solution based on the comparatively high pseudo f-score (2.25) and the interpretability of the proposed clusters. The four-cluster solution had the highest pseudo f-score (3.13) indicating that it had the most distinct clusters. However, we discounted this solution as it did not identify the early intervention group which we felt was an important, policy relevant group given the focus on early intervention in the English care system (Allen, 2011). The pseudo fscore of the five-cluster solution was also marginally higher than the six-cluster solution (2.36 vs 2.25$)$. However, we discounted it as it aggregated the stable $1^{\text {st }}$ placement and stable $2^{\text {nd }}$ placement groups which differed in terms of circumstances surrounding first entry to care (e.g., $6.3 \%$ of the stable $1^{\text {st }}$ placement entered care via child protection orders compared to $19.4 \%$ of the stable $2^{\text {nd }}$ placement subgroup; $p<0.0001$ ) and final exit from care (e.g., $15.8 \%$ of the stable $1^{\text {st }}$ placement moved to an adult social care institution when leaving care for the final time compared to $7.1 \%$ of the stable $2^{\text {nd }}$ placement subgroup; $p=0.0005$ ). 